6-1-2011

\title{
Why do some small islands lack vegetation? Evidence from long- term introduction experiments
}

Lloyd W. Morrison

Missouri State University

Follow this and additional works at: https://bearworks.missouristate.edu/articles-cnas

\section{Recommended Citation}

Morrison, Lloyd W. "Why do some small islands lack vegetation? Evidence from long-term introduction experiments." Ecography 34, no. 3 (2011): 384-391.

This article or document was made available through BearWorks, the institutional repository of Missouri State University. The work contained in it may be protected by copyright and require permission of the copyright holder for reuse or redistribution.

For more information, please contact BearWorks@library.missouristate.edu. 


\title{
Why do some small islands lack vegetation? Evidence from long-term introduction experiments
}

\author{
Lloyd W. Morrison
}

L.W. Morrison(lloydmorrison@missouristate.edu), Dept of Biology, Missouri State Univ., 901 S. National Avenue, Springfield, MO 65897, USA.

\begin{abstract}
Classic island biogeography theory predicts that very small islands, near the extreme lower end of the species-area relationship, should support very few species. At times no species may be present, however, due to randomness in the immigration-extinction dynamics. Alternatively, a lack of vegetation on very small islands may indicate that such islands do not contain the appropriate habitat for the establishment or long-term survival of plants, or that disturbances are too frequent or intense. These potential mechanisms were evaluated in the central Exumas, Bahamas, where surveys of 117 small islands revealed that over a third of the islands supported no terrestrial plant life. Area and exposure were significant predictors of whether a small island was vegetated or not in multiple logistic regressions. No islands naturally devoid of vegetation were colonized over a $17-y r$ period, and only two naturally vegetated islands lost all vegetation. Experimental introductions of two species - Sesuvium portulacastrum and Borrichia arborescens - revealed that a number of islands naturally lacking vegetation were able to sustain introduced populations over the long term (up to 15 yr). Drought and hurricanes appeared to have reduced the establishment success and possibly long-term survival of the introductions, although some populations survived four major hurricanes. Turnover rates of both introduced species were often an order of magnitude higher on the experimental introduction islands than on other islands in the archipelago. It appears many of the islands in this system that naturally lack vegetation may be physically capable of supporting terrestrial plant life, yet have no plants primarily due to barriers to colonization.
\end{abstract}

The theory of island biogeography (MacArthur and Wilson 1963, 1967) predicts that the species richness of an island or habitat fragment will remain relatively constant over time, while the species composition changes, resulting in a state of dynamic equilibrium. This elegant theory has been the impetus for many observations and manipulations of insular systems (reviewed in Lomolino et al. 2006, Whittaker and Fernández-Palacios 2007), and it remains useful for evaluating basic biogeographical patterns and processes (Losos and Ricklefs 2009).

The classic theory predicts that the smaller or more remote an island, the fewer species should be present. While the distance effect has been difficult to evaluate and the outcomes of tests of this effect are often equivocal (Whittaker and Fernández-Palacios 2007), the species-area relationship is recognized as one of the few "genuine laws" in ecology (Schoener 1976). Often, however, species richness does not increase with area on the smallest islands in an archipelago, a phenomenon referred to as the "small island effect" (Wiens 1962, Niering 1963, MacArthur and Wilson 1967, Whitehead and Jones 1969, Lomolino 2000, Lomolino and Weiser 2001, Triantis et al. 2006, Burns et al. 2009). Although not discussed explicitly by the theory, it logically follows that, in the extreme case, very small islands may only be able to support one or two species, and may have no species at all at a given point in time, due to random variability in the immigration-extinction dynamics.

An alternative explanation for an island with no species is that the island is not suitable physically; the organism of interest simply cannot survive there at any time. It is not always obvious which may be the case, however, because turnover rates for many species, particularly vascular plants, are relatively low (Schoener 1983, Morrison 1997, 2003, Vidal et al. 2000, Cody 2006, Panitsa et al. 2008). In fact, the immigration-extinction dynamics characterizing very small islands may not become obvious for decades (Morrison 2010).

The many small, rocky islands of the Bahamas provide an opportunity to address this issue both observationally and experimentally, and determine whether islands that lack vegetation do so because they are physically unsuitable, or because colonization is very infrequent (or extinction relatively frequent). Surveys of 117 small islands $\left(<6000 \mathrm{~m}^{2}\right)$ in the Exuma Cays conducted in 1990 revealed that over a third of the islands supported no terrestrial vegetation (Morrison 1997). Experimental introductions of two species revealed that some of these "empty" islands could in fact support terrestrial vegetation, at least for a few years during relatively benign climatic periods (Morrison 1997, 2003). More recently, four major hurricanes have impacted this region of the Bahamas, and a significant increase in 
temperature and decline in precipitation is now evident over the past quarter century (Morrison 2010). Here I investigate the island characteristics that determine suitability for terrestrial vegetation in this system, and describe the entire 15-yr history of the introductions.

The following questions are addressed: 1) what are the most important island attributes in determining whether small islands have terrestrial vegetation? 2) Are small islands naturally lacking terrestrial vegetation physically able to support plant life in the long-term? 3) Is the presence or absence of terrestrial plant life on small islands stable over the long-term? 4) What are the underlying mechanisms?

\section{Methods}

\section{Study area and general surveys}

This study was conducted on small islands in the Exuma Cays archipelago of the central Bahamas (Fig. 1). Islands were composed primarily of marine limestone, with some islands consisting of small amounts of fossil sand deposits or loose sand. The broader area surveyed for the presence or absence of terrestrial vegetation included 117 small islands occurring within the $13.5 \mathrm{~km}$ island chain between O'Briens Cay $\left(24^{\circ} 19^{\prime} \mathrm{N}, 76^{\circ} 33^{\prime} \mathrm{W}\right)$ and Bitter Guana Cay $\left(24^{\circ} 08^{\prime} \mathrm{N}, 76^{\circ} 25^{\prime} \mathrm{W}\right)$. All islands $<6000 \mathrm{~m}^{2}$ in area were included. Surveys of the floras of these small islands in May of 1990 documented that 40 out of the 117 islands had no terrestrial vegetation (Morrison 1997). All 117 islands have been surveyed 7 additional times over a 17-yr period: in 1991, 1992, 1993, 1994, 1998, 2003, and 2007, always during the month of May. (Islands to which vegetation was experimentally introduced were surveyed at different intervals; see below.) Over 50 terrestrial plant species have been documented from the small islands surveyed (Morrison 2003).

All experimental islands, to which species were introduced, lay between Pipe Cay $\left(24^{\circ} 14^{\prime} \mathrm{N}, 76^{\circ} 30^{\prime} \mathrm{W}\right)$ and Bitter Guana Cay. Experimental islands were composed almost entirely of marine limestone, and contained no trace of any terrestrial vegetation. Islands were not completely devoid of life, however; a relatively diverse arthropod assemblage occupied such islands, including representatives of 10 orders (Morrison 2005).

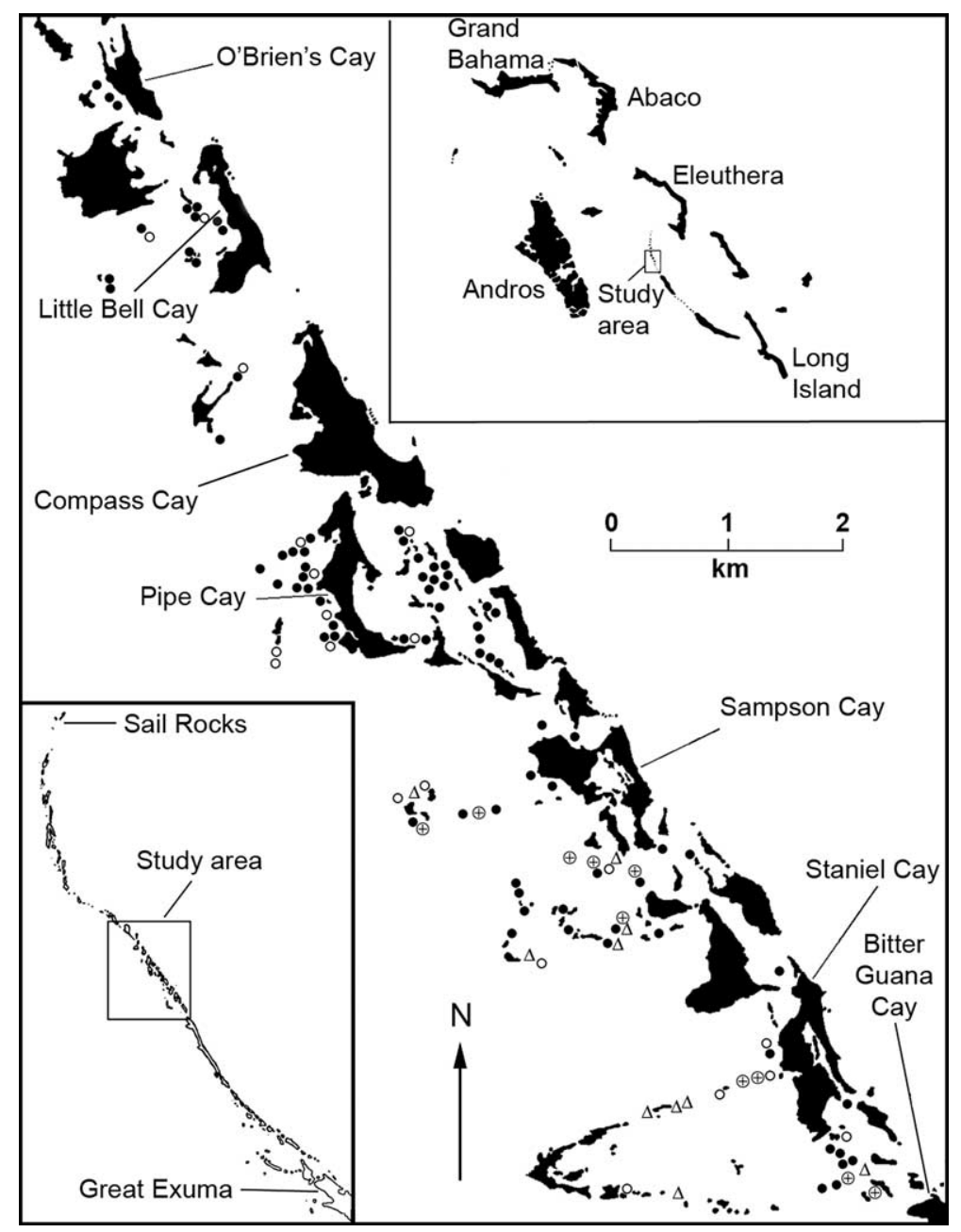

Figure 1. Map of the study area. Lower left inset shows the location of the study area within the Exuma Cays. Upper right inset depicts the study area in relation to the north-central Bahamas. Legend: surveyed islands with vegetation in 1990; O surveyed islands with no vegetation in 1990; $\oplus$ surveyed islands with no vegetation in 1990 and $S$. portulacastrum introduced in $1992 ; \Delta$ surveyed islands with no vegetation in 1990 and B. arborescens introduced in 1998. 


\section{Experimental introductions}

Two plant species were experimentally introduced to small islands that were naturally devoid of vegetation (see Morrison 2003 for a rationale for the species selected). Sesuvium portulacastrum - a succulent, salt-tolerant, perennial herb - was introduced to ten non-vegetated islands in May 1992. Three vegetative propagules were planted on each island (see Morrison 1997 for a complete description). Islands with surviving populations were re-visited 12 times over a 15 yr period: May 1993, May 1994, October 1995, May 1998, May 1999, September 1999, September 2000, September 2001, December 2002, May 2003, December 2003, and May 2007. At each visit, the twodimensional vegetated area of $S$. portulacastrum was measured.

A second salt-tolerant perennial herb, Borrichia arborescens, was introduced to five non-vegetated islands in May 1998 , and to five additional non-vegetated islands in October 1998. Four small plants of equal size $(\sim 10 \mathrm{~cm}$ tall) were planted in different locations on each island (see Morrison 2003 for a complete description). Islands with surviving populations were re-visited at the same intervals as S. portulacastrum, beginning in May 1999.

\section{Analyses}

Stepwise multiple logistic regressions were employed to test whether the occurrence of vegetation on an island was related to four physical island variables. The predictor variables evaluated were: 1) total island area, 2) elevation, 3) distance, and 4) exposure to wind and waves. Elevation was measured as the vertical distance from the mean tide mark to the highest part of the island. Distance was measured from the nearest "mainland" island, which was any island $>46580 \mathrm{~m}^{2}$. This threshold is based on a natural discontinuity of island area in the region (Schoener 1987). To quantify exposure to wind and waves, a circle was drawn around each island with a radius of $1 \mathrm{~km}$ from the island center. For every neighboring island within the circle or in contact with the circumference of the circle, the arc of the circle obstructed by the neighboring island was measured, and all obstructed arcs were summed. The sum of obstructed arcs was subtracted from 360, so that higher values of the metric would be associated with greater exposure. This measure of exposure could range from 0 (when the island in question was completely surrounded by islands in all directions) to 360 (in the case where no other islands were near and the island was exposed on all sides) (see Morrison 2002, for a complete description of this technique).

All predictor variables were preliminarily evaluated on a univariate basis before running the stepwise procedure (as recommended by Hosmer and Lemeshow 2000). Both forward and backward stepwise procedures using the likelihood-ratio statistic were employed; variables were included in the model at the $\mathrm{p}=0.05$ level and removed if $\mathrm{p}$ exceeded 0.10 . The 100 smallest islands (of 117 total) were included in this analysis, which included all islands naturally lacking vegetation.
Turnover rates of the two introduced species were calculated on a per species basis (a metapopulation approach; Morrison 1997) as:

Relative turnover $=\frac{(I+E)}{\left(S_{1}+S_{2}\right)} \times 100$

where $S_{1}$ and $S_{2}$ were the number of islands on which a particular species was present at the beginning and end, respectively, of a survey interval; $E$ and I were the number of islands on which a species was found only at the beginning and only at the end, respectively, of a survey interval. Rates were annualized by dividing relative turnover by the number of years intervening between surveys.

Physical attributes of islands (area, elevation, distance, and exposure) on which $S$. portulacastrum did persist were compared to islands where extinctions occurred with logistic regression analyses. A separate regression was performed for each island attribute, with the presence or absence of $S$. portulacastrum in the last survey as the response variable. SPSS 16.0.1 for Mac OSX (SPSS 2007) was used for all analyses.

\section{Hurricane activity and precipitation}

Four hurricanes affected the study areas from 1999 to 2004. In September 1999, Hurricane Floyd, a large, intense, category 4 storm on a northwesterly track, hit the Bahamas. Conditions in the Exuma Cays, $\sim 100 \mathrm{~km}$ from the eye of the storm, approximated a category 2 hurricane (Pasch et al. 1999). Long-term residents of Staniel Cay, in the Exumas archipelago, indicated in interviews that Floyd had the greatest impacts in the Exumas of any hurricane since 1929. In November 2001, Hurricane Michelle crossed the Bahamas from southwest to northeast. Although weakening as it moved over the Bahamas, Michelle still produced sustained winds of 70-80 knots (category 1), and storm surges affected the study area (Beven 2002). Hurricane Frances moved across the length of the Bahamas archipelago on a northwesterly track in September 2004, a category 3 storm over the central Bahamas (Beven 2004). Hurricane Jeanne, also in September 2004, moved across the northern Bahamas as a category 3 storm (Lawrence and Cobb 2004). Effects on the Exumas were less severe than those of Frances earlier in the month.

Data on annual number of days with rain were obtained from the Nassau International Airport on New Providence $\left(25^{\circ} 03^{\prime} \mathrm{N}, 77^{\circ} 28^{\prime} \mathrm{W}\right)$ for the last quarter century (1983-2007). Descriptive comparisons are made among years in relation to the experimental introductions; for an analysis of precipitation and temperature trends over time, see Morrison (2010).

\section{Results}

\section{Determinants of island suitability to support vegetation}

All four predictor variables evaluated in the univariate logistic regressions - area, elevation, distance, and exposure - were significant predictors of the occurrence of 
vegetation (Table 1). Island area was positively correlated with elevation $(r=0.60, p<0.001)$, and exposure was positively correlated with distance $(\mathrm{r}=0.40, \mathrm{p}<0.001)$; no other pairs of variables were significantly correlated (all $\mathrm{p}>0.2$ ). In the stepwise multiple logistic regressions, island area and exposure were selected as significant predictor variables in the final multivariate model, by both the forward selection and backward elimination procedures (Table 1).

Thus islands lacking vegetation tended to be smaller, lower, more distant from mainland islands, and more exposed to winds and waves, although once island size and exposure were taken into account, neither elevation nor distance increased the predictive power of the model. The predictive power of the multivariate model was greater than that of any of the univariate models, based on the logistic summary measures (Table 1). Plotting the islands by area and exposure reveals a relatively large amount of stochasticity in whether islands had vegetation; this variability is more pronounced along the exposure axis (Fig. 2).

\section{Experimental introductions}

The vegetated areas of introduced $S$. portulacastrum populations generally increased over the first seven years, before suffering the first of three declines (Fig. 3). All three were associated with hurricane activity: 1) Hurricane Floyd in September 1999, 2) Hurricane Michelle in November 2001, and 3) the combined effects of Hurricanes Frances and Jeanne in September 2004. Populations on most islands reached their greatest vegetated areas before Floyd, and never recovered those levels. A visit to the experimental islands $11 \mathrm{~d}$ after Floyd revealed extensive damage to S. portulacastrum on all islands. On many islands, only short, broken sections of older, thicker stems, devoid of any leaves, remained. On some islands, the root system was exposed, and soil had been scoured away.

Over a year elapsed following Michelle before the next visit, and such damage was not obvious. Populations declined overall after Michelle, except for two islands that did not seem to be adversely affected. Frances/Jeanne seemed to have the least impact of this series of storms based on the line plot in Fig. 3, although the experimental islands were not revisited until $31 / 2 \mathrm{yr}$ after Frances/ Jeanne. Thus the vegetated areas may have decreased much more due to these storms than indicated by the figure, and rebounded before the May 2007 visit. The intervals between visits surrounding Floyd and Michelle were much shorter.

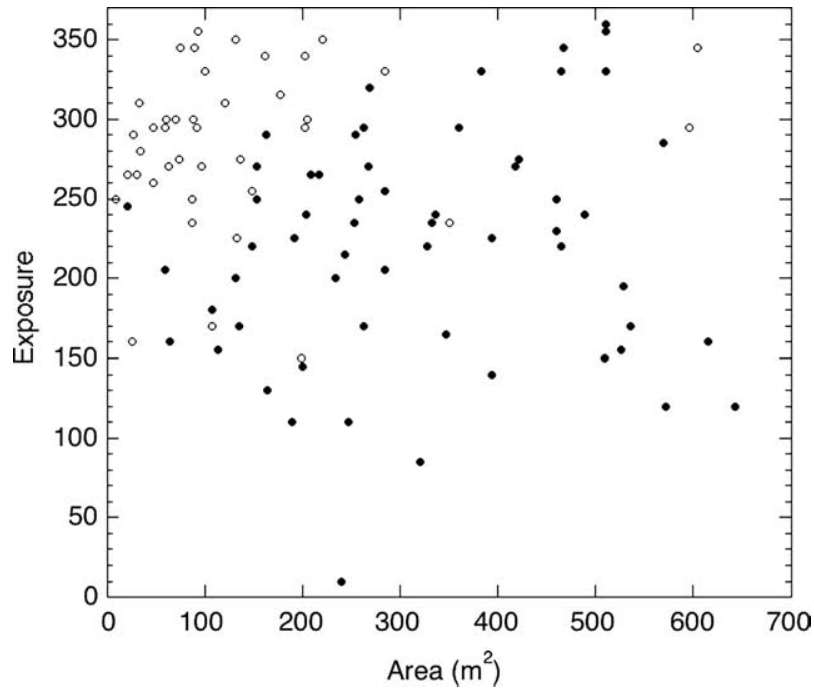

Figure 2. Islands with (filled circles) and without (open circles) terrestrial vegetation as a function of area and exposure. Exposure could range from 0 (when the island in question was completely surrounded by islands in all directions) to 360 (in the case where no other islands were near). The 100 smallest islands are shown; no larger islands lacked terrestrial vegetation.

By the last survey in May 2007, half of the introduced populations remained. The percentage of populations surviving as a function of time strongly resembles a linear process $(r=0.97$; Fig. 4). Because revisits were not always done at constant intervals, however, this interpretation must be viewed with caution. Comparison of before and after surveys revealed that no extinctions were directly due to Floyd. One extinction occurred in the interval associated with Michelle, and two in the interval associated with the combination of Frances/Jeanne. Thus, the last three extinction events were associated with hurricane intervals, although the last interval was relatively long.

Evaluation of island area, elevation, distance, and exposure as predictors of population persistence yielded a marginally significant result for elevation (univariate logistic regression; $\chi^{2}=3.11, \mathrm{p}=0.078, \mathrm{DF}=1$ ), as populations were more likely to persist on higher islands. No other predictors approached significance (all $\mathrm{p}>0.25$ ), although sample sizes were relatively small.

Borrichia arborescens survived on three of the initial five introduction islands from May to October 1998, in each case represented by a single individual. By May 1999 , B. arborescens was present on only two of the ten islands to which it had been transplanted (one from the

Table 1. Results of logistic regressions.\% Correct = percentage of islands correctly classified by the model containing the indicated variables. The 100 smallest islands (of the 117 total) were included in the analyses.

\begin{tabular}{|c|c|c|c|c|c|c|}
\hline Variable & Coefficient & Constant & Significance $(p)$ & $\%$ Correct & Cox and Snell $R^{2}$ & Nagelkerke $\mathrm{R}^{2}$ \\
\hline \multicolumn{7}{|l|}{ Univariate } \\
\hline Area & 0.009 & -1.525 & $<0.001$ & 77.0 & 0.277 & 0.375 \\
\hline Elevation & 1.168 & -1.200 & 0.002 & 55.0 & 0.103 & 0.139 \\
\hline Distance & -0.001 & 1.008 & 0.003 & 67.0 & 0.086 & 0.116 \\
\hline Exposure & -0.017 & 4.750 & $<0.001$ & 72.0 & 0.207 & 0.280 \\
\hline \multicolumn{7}{|l|}{ Multivariate } \\
\hline Area, Exposure* & $0.011,-0.025$ & -4.361 & $<0.001$ & 87.0 & 0.448 & 0.606 \\
\hline
\end{tabular}

*The same model was chosen as significant by both forward and backward stepwise procedures. 


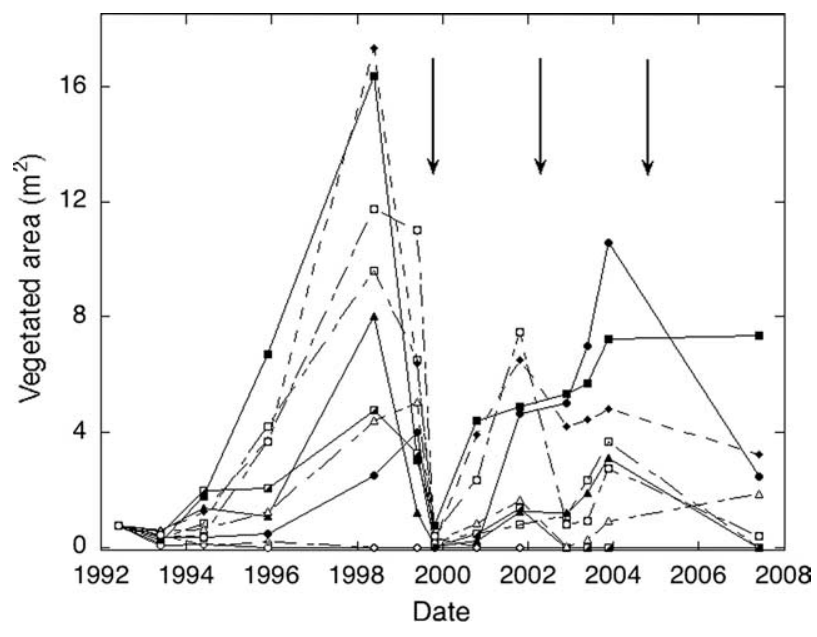

Figure 3. The vegetative area of introduced $S$. portulacastrum populations over time. All 10 experimental islands are plotted. Arrows indicate (from left to right) Hurricanes Floyd, Michelle, and Frances/Jeanne.

May and one from the October transplants). In both cases, only a single plant remained. In September 1999, after Hurricane Floyd, only the transplant from May 1998 remained; many leaves were necrotic, and new stems sprouted from the rhizomes. By the last survey in May 2007, the transplant from May 1998 still survived and appeared healthy.

\section{Long-term immigration-extinction dynamics of natural populations}

Of the 40 islands that had no vegetation in 1990, none were naturally colonized by any plant species between 1990 and 2007. Of the 77 islands that had vegetation in 1990, two islands lost all vegetation, and this occurred between 2003 and 2007 in both cases. On one island, only B. arborescens

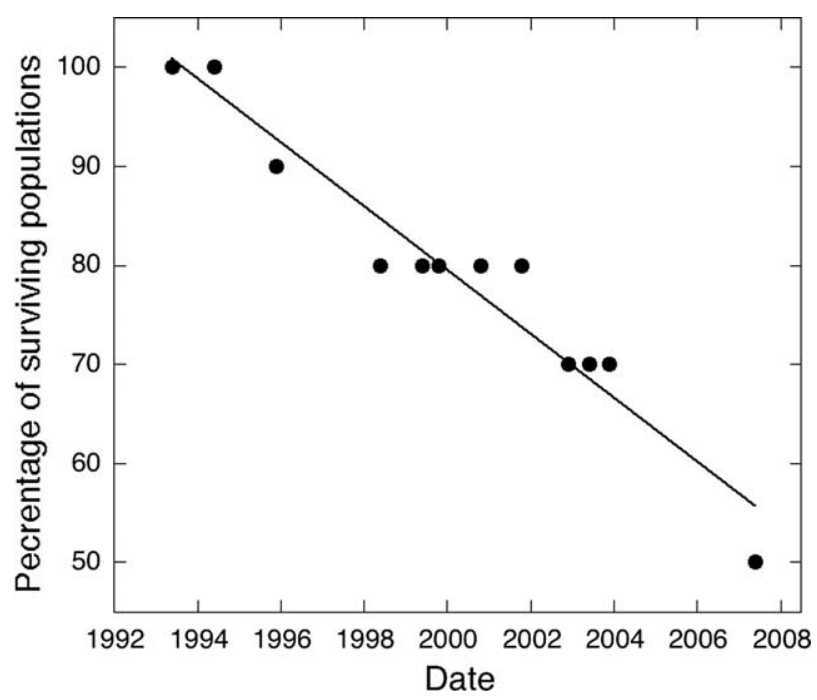

Figure 4. Percentage of surviving populations of $S$. portulacastrum over time. Line of best fit from a linear regression is plotted $(\mathrm{y}=$ $-3.23 \mathrm{x}+6533, \mathrm{r}=0.97, \mathrm{p}<0.001, \mathrm{DF}=11)$. had been present, and on the other, only $S$. portulacastrum had been present, both dating back to the earliest survey in 1990. Overall turnover rates for naturally vegetated islands may be found in Morrison (2010).

In $1990, B$. arborescens was present on 48 of the 77 vegetated islands $(62 \%)$, and $S$. portulacastrum was present on 36 (47\%). Thus, many islands had the potential to gain or lose each species. Yet natural populations of $S$. portulacastrum and $B$. arborescens were characterized by low turnover rates, always $<1 \%$, and often 0 , depending upon the interval (Table 2). Only a single immigration event was recorded. All of the extinctions occurred during the latter survey intervals; this was consistent with a broad general decline in the floras of these small islands since the late 1990s (Morrison 2010).

Introduced populations of $S$. portulacastrum and $B$. arborescens experienced higher rates of turnover than natural populations, often by an order of magnitude: $2.2 \%$ $\mathrm{yr}^{-1}$ over the entire 15 -yr period for $S$. portulacastrum and $7.4 \% \mathrm{yr}^{-1}$ over the 9 -yr period for B. arborescens. (All turnover events were extinctions in both cases.)

\section{Discussion}

\section{Barriers to colonization}

Low immigration rates appear to be one reason that many islands may have no species. Only a single natural colonization by $S$. portulacastrum - and no natural colonizations by $B$. arborescens - occurred during the course of this study. The limiting factor may be arrival on the island, as many of these islands have relatively steep sides, and floating propagules may not easily be washed up on an island.

Alternatively, establishment may be limiting. Both species that were introduced were established by planting multiple propagules within the soil of potholes on the islands. Pilot attempts were made to introduce the three other salt-tolerant species that are common in the archipelago - C. erectus, S. maritima, and $R$. americana - to four islands without vegetation. Sowing experiments with seeds of first two, along with attempts to transplant vegetative propagules of the third, failed to produce any established populations (unpubl.). Sowing experiments with seeds or propagules on small islands in the Mediterranean also yielded very low success rates (Höner and Greuter 1988). Examination of 30 of these small Bahamian islands within one month after Hurricane Floyd revealed that potential vegetative propagules of several species (including $S$. portulacastrum, but not $B$. arborescens) had been washed up on them. No species became established on islands that were devoid of vegetation, however, and no increase in immigration rates on naturally vegetated islands occurred (Morrison 2003, 2010).

Thus, while many of these islands may be able to support plants of some critical size that are placed in a suitable location and buried or rooted in the soil, it appears that it is extremely difficult for seeds or propagules strewn randomly about the surface of the island to become established. 
Table 2. Rates of annual relative turnover ( $\%$ islands $\mathrm{yr}^{-1}$ ), number of immigrations, and number of extinctions, for naturally occurring populations of Borrichia arborescens and Sesuvium portulacastrum on 77 islands in the Exuma Cays archipelago of the Bahamas over 4 multi-year intervals.

\begin{tabular}{lcccccc}
\hline Interval & \multicolumn{3}{c}{ Borrichia arborescens } & & \multicolumn{2}{c}{ Sesuvium portulacastrum } \\
\cline { 2 - 3 } & Turnover & Immigrations & Extinctions & & Turnover Immigrations \\
\hline $1990-1994$ & 0 & 0 & 0 & 0.34 & 0 \\
$1994-1998$ & 0 & 0 & 0 & 0 & 0 \\
$1998-2003$ & 0.21 & 0 & 1 & 0 & 0 \\
$2003-2007$ & 0.84 & 0 & 3 & & 0.69 & 0 \\
\hline
\end{tabular}

\section{Effects of hurricanes and climate change on introductions}

Chronic disturbance from hurricanes is one explanation for the failure of most $S$. portulacastrum populations to reach the peak vegetated areas observed before Floyd. Although mechanical damage and removal of plant biomass was observed immediately after Floyd, the more important and longer lasting effects may have been indirect. For example, herbivory was found to be higher in this island system in the aftermath of hurricanes (Spiller and Agrawal 2003, Spiller and Schoener 2007). At least one herbivore of $S$. portulacastrum, Achyra rantalis (Lepidoptera: Crambidae), has been documented to reduce the abundance of $S$. portulacastrum on larger islands in this region (T. W. Schoener and D. A. Spiller pers. comm.). Achyra rantalis was often observed on the experimental introduction islands, and leaf scars characteristic of Achyra rantalis damage were commonly noted.

Another possibility is that wind or wave action associated with Floyd (and later hurricanes) removed soil or nutrients from these small islands. Alternatively, $S$. portulacastrum in its initial rapid growth phase may have depleted the available nutrients. In either case, the islands may have been less fertile after 1999 .

The regional climate has changed over the past quarter century, becoming both warmer and drier. From 1983 to 2007, annual mean maximum temperature increased by $0.6^{\circ} \mathrm{C}$, from 28.53 to $29.13^{\circ} \mathrm{C}$; annual mean minimum temperatures increased by $1.47^{\circ} \mathrm{C}$, from 19.75 to $21.22^{\circ} \mathrm{C}$. The annual number of days with rain decreased by 18 , from 147 to 129 (Morrison 2010). Total annual precipitation did not change, although number of days with rain is probably a better indicator of the fresh water available to vegetation on these islands. Due to their small size and rocky substrate, only limited amounts of rainfall can be absorbed (most of it runs off), and heavy rainfall events would likely contribute proportionately little more fresh water compared to more moderate events. Such climate change may also have resulted in greater herbivory, which is known to increase due to drought and other forms of environmental stress (Larsson 1989, Ayres 1993).

Differences in survival of the two species may be attributable primarily to climatic conditions during and after the transplant attempts. The years in which the transplants of both species were made, 1992 and 1998, turned out to be two of the driest years of the past quarter century; only two other years (2004 and 2005) had fewer days with rain (Fig. 5). The distribution of rainfall was not similar across the two years, however. The total number of days of rain for the three-month period May-July 1992 (S. portulacastrum was transplanted in May 1992) was only a single day below the long-term (25-yr) average. By contrast, the precipitation deficit for May-July 1998 and October-December 1998 (B. arborescens was transplanted in May and October 1998) were 11 and $7 \mathrm{~d}$, respectively, below the long-term average. Soil moisture in the establishment stage of such propagules is likely to be critical, and transplants of $B$. arborescens were made at times when it was much drier than the transplants of $S$. portulacastrum. Other factors that could potentially result in differences in survival of the two species are discussed in Morrison (2003).

\section{Potential mechanisms and species-area analogies}

The fact that five out of ten of the $S$. portulacastrum introductions have persisted for at least $15 \mathrm{yr}$, and one of the ten $B$. arborescens introductions has persisted for at least $9 \mathrm{yr}$, indicates that not all islands naturally lacking terrestrial plant life in this system are physically unsuitable for vegetation. Moreover, other islands of similar or even smaller dimensions have had persistent terrestrial vegetation throughout the 17-yr history of this study.

Attempting to elucidate the mechanisms underlying the ability of small islands to support terrestrial vegetation is analogous to investigating the factors responsible for the ubiquitous species-area relationship (Connor and McCoy

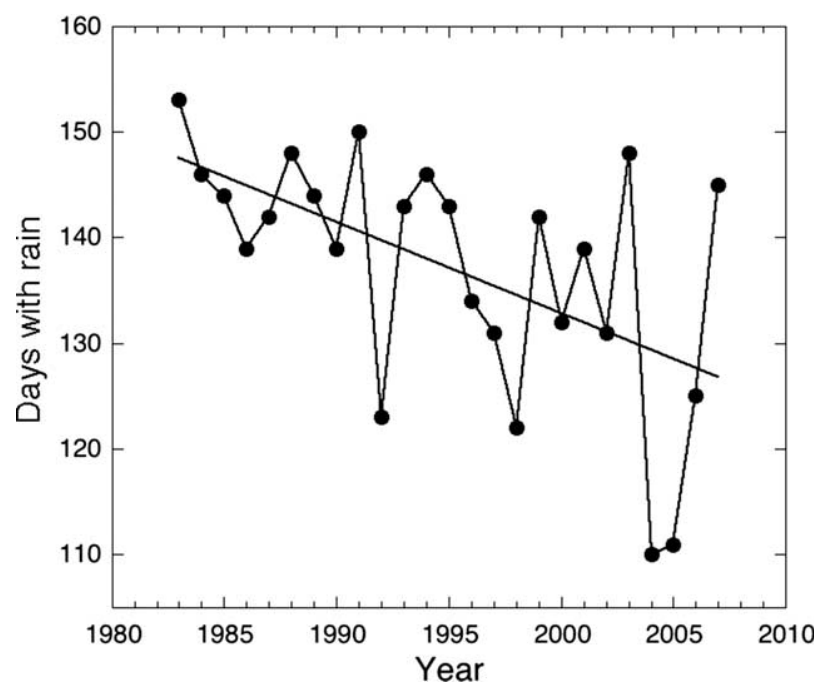

Figure 5. Cumulative number of days with measurable precipitation by year, from 1983 to 2007 . The negative trend is significant $(\mathrm{F}=8.20, \mathrm{p}=0.009, \mathrm{DF}=24, \mathrm{y}=-0.74 \mathrm{x}+1600.28$; weighted least squares regression; Morrison 2010). 
1979), near the extreme end of the curve where both island area and species number approach zero. For the smallest islands in an archipelago, a number of studies have reported that below a certain threshold, species richness is independent of island size (Niering 1963, MacArthur and Wilson 1967, Morrison 1997, Lomolino and Weiser 2001, Gentile and Argano 2005, Triantis et al. 2006). Although this "small island effect" is usually described in terms of species richness rather than the presence or absence of species, the mechanisms underlying the small island effect could also play a role in determining whether or not any species are present on the smallest islands. In general, the small island effect is likely to be shaped by different factors in different archipelagos, and may result from characteristics of the taxa in question, general characteristics of the islands, as well as stochastic events (Triantis et al. 2006).

A number of mechanisms have been advanced to explain the species-area relationship (Connor and McCoy 1979, McGuinness 1984, Kelly et al. 1989), and at least three are relevant in the extreme case represented here: 1) one is the equilibrium hypothesis (sometimes called the area per se hypothesis) (Preston 1960, 1962a, b, MacArthur and Wilson 1963, 1967) which, in the case of very small islands, could be interpreted as the presence or absence of vegetation being a function of random immigration/ extinction dynamics. Thus, any given island with some emergent area may or may not have vegetation at a specific point in time, but over time would eventually be colonized (and suffer extinctions).

2) The habitat diversity hypothesis proposes that as area increases, so does the number of new habitats and their associated species (Williams 1964). In the extreme case of very small islands, the question becomes whether the appropriate habitat components for the survival of terrestrial plants exist (i.e. the basic availability of soil, nutrients, and freshwater). If not, these islands could not support terrestrial plant life at all. 3) The disturbance hypothesis (McGuinness 1984) posits that disturbances such as storms reduce species numbers, and the frequency and intensity of these events increase with decreasing island area. In the present case, disturbances from breaking waves and high tides are frequent on the small low-lying islands, and total submergence during storms is not uncommon. Thus vegetation, once established, might survive until a storm or other disturbance caused it to go extinct, and the island could be colonized again. In the extreme case, disturbances may be too frequent to allow establishment or survival (except possibly for brief intervals).

Over a 17-yr period, no natural colonizations of very small islands were recorded, and only 2 of 77 islands with vegetation in 1990 lost all vegetation. This indicates that the first explanation, if in existence, operates over very long time periods (i.e. centuries). Barriers to colonization may result in low immigration rates. The documented long-term survival of the two introduced species on multiple islands seems to indicate that some of the islands do possess the appropriate habitat. Islands on which introduced populations have gone extinct may have been physically unsuitable, or at least marginally so. The monotonic decline in established populations (Fig. 4) could be interpreted as a prediction that all introduced populations will eventually go extinct, although there is no guarantee this process will continue, or at least at the same rate. Nutrients may be in short supply in the shallow soils of these predominantly rocky islands, and be depleted relatively quickly. Ultimately, the question of whether suitable habitat exists may depend upon how long a population is required to persist on an island.

The flora inhabiting these archipelagos is strongly nested (Morrison 1997), and only a small number of species would be expected to survive on such small islands. In addition to the two species introduced, three other salttolerant species - Conocarpus erectus, Suriana maritima and Rhachicallis americana - each occur on more than one-third of the small islands in this system (Morrison 2003). Fifteen additional species have been observed on islands $<300 \mathrm{~m}^{2}$. This suggests that up to 20 species could survive on many of the islands devoid of vegetation if they could become established.

Regarding the disturbance hypothesis, hurricane activity may have caused a maximum of four extinctions (three of $S$. portulacastrum and one of B. arborescens). Storms of lesser intensity, but occurring with greater frequency, combined with high tides, could result in strong wave action and submergence of these small islands, producing a series of smaller disturbances over time. The logistic regression results support the importance of disturbance from wave action as a barrier to plant establishment or survival. Islands that are smaller, lower, more exposed, or more distant from larger, protective islands will experience greater impacts from high waves or storm surges. It does seem certain that the relatively large number of naturally non-vegetated islands is not the result of an extinction pulse due to a major hurricane that occurred before the surveys: no major hurricanes struck anywhere in the Exumas between 1932 and 1996 (Spiller et al. 1998).

Abnormally dry conditions following the introductions are the likely reason most $B$. arborescens propagules failed to become established. The long-term climate change documented in the region may be responsible for the gradual extinction of $S$. portulacastrum populations or decline in vegetated areas. Without the unusually hot and dry weather following the introductions, or the series of hurricanes, more introduced populations may have persisted.

\section{Conclusions}

The introduction experiments revealed that many of the islands in this system that were devoid of vegetation are capable of sustaining some species for years, if not decades. Some introductions have endured four major hurricanes and an unknown number of smaller storms. Thus, while it is possible that some islands may lack the basic habitat or that some introductions were eradicated by disturbances, a barrier to colonization appears to be the primary mechanism underlying the relatively large number of islands with no vegetation. Although the habitat may be marginal, and the number of potential colonists few, the available evidence indicates that more than one species could survive over the moderate to long term if they could become established.

If a barrier to colonization is the main factor responsible for so many small islands lacking vegetation, and the same mechanisms operate on larger islands, the implications for 
larger islands in this system would include relatively low rates of immigration or species turnover. This is exactly what has been found: from 1990 to 2007 in this archipelago, $<0.07$ immigrations occurred per island per year, and $<2 \%$ of the species present turned over per year (Morrison 2010). It would be of great interest to investigate the long-term dynamics of very small islands in other oceanic archipelagos, to see if similar patterns exist.

Acknowledgements - This work was supported by National Geographic Society grants (7447-03 and 8137-06) to the author, and NSF grants to T. W. Schoener and D. A. Spiller. I thank Mary Butler in the Dept of Meteorology at Nassau for providing the rainfall records. K. Triantis and M. V. Lomolino provided helpful comments on the manuscript.

\section{References}

Ayres, M. P. 1993. Plant defense, herbivory, and climate change. - In: Karieva, P. M. et al. (eds), Biotic interactions and global change. Sinauer Associates, pp. 75-94.

Beven, J. 2002. Tropical cyclone report: hurricane Michelle. - National Hurricane Center, Miami, FL.

Beven, J. L. I. 2004. Tropical cyclone report: hurricane Frances: 25 August-8 September 2004. - National Hurricane Center, Miami, FL.

Burns, K. C. et al. 2009. The small island effect: fact or artefact? - Ecography 32: 269-276.

Cody, M. L. 2006. Plants on islands: diversity and dynamics on a continental archipelago. - Univ. of California Press.

Connor, E. F. and McCoy, E. D. 1979. The statistics and biology of the species-area relationship. - Am. Nat. 113: 791-833.

Gentile, G. and Argano, R. 2005. Island biogeography of the Mediterranean sea: the species-area relationship for terrestrial isopods. - J. Biogeogr. 32: 1715-1726.

Höner, D. and Greuter, W. 1988. Plant population dynamics and species turnover on small islands near Karpathos (South Aegean, Greece). - Vegetatio 77: 129-137.

Hosmer, D. W. and Lemeshow, S. 2000. Applied logistic regression. - Wiley.

Kelly, B. J. et al. 1989. Causes of the species-area relation: a study of islands in Lake Manapouri, New Zealand. - J. Ecol. 77: 1021-1028.

Larsson, S. 1989. Stressful times for the plant stress-insect performance hypothesis. - Oikos 56: 277-283.

Lawrence, M. B. and Cobb, H. D. 2004. Tropical cyclone report: hurricane Jeanne: 13-28 September 2004. - National Hurricane Center, Miami, FL.

Lomolino, M. V. 2000. Ecology's most general, yet protean, pattern: the species-area relationship. - J. Biogeogr. 27: 1726.

Lomolino, M. V. and Weiser, M. D. 2001. Towards a more general species-area relationship: diversity on all islands, great and small. - J. Biogeogr. 28: 431-445.

Lomolino, M. V. et al. 2006. Biogeography. - Sinauer Associates.

Losos, J. B. and Ricklefs, R. E. (eds) 2009. The theory of island biogeography revisited. - Princeton Univ. Press.

MacArthur, R. H. and Wilson, E. O. 1963. An equilibrium theory of insular zoogeography. - Evolution 17: 373-387.

MacArthur, R. H. and Wilson, E. O. 1967. The theory of island biogeography. - Princeton Univ. Press.
McGuinness, K. A. 1984. Equations and explanations in the study of species-area curves. - Biol. Rev. 59: 423-440.

Morrison, L. W. 1997. The insular biogeography of small Bahamian cays. - J. Ecol. 85: 441-454.

Morrison, L. W. 2002. Determinants of plant species richness on small Bahamian islands. - J. Biogeogr. 29: 931-941.

Morrison, L. W. 2003. Plant species persistence and turnover on small Bahamian cays. - Oecologia 136: 51-62.

Morrison, L. W. 2005. Arthropod diversity and allochthonousbased food webs on tiny oceanic islands. - Divers. Distrib. 11: 517-524.

Morrison, L. W. 2010. Long-term non-equilibrium dynamics of insular floras: a 17-year record. - Global Ecol. Biogeogr. 19: 663-672.

Niering, W. A. 1963. Terrestrial ecology of Kapingamarangi Atoll, Caroline Islands. - Ecol. Monogr. 33: 131-160.

Panitsa, M. et al. 2008. Turnover of plants on small islets of the eastern Aegean Sea within two decades. - J. Biogeogr. 35: 1049-1061.

Pasch, R. J. et al. 1999. Preliminary report: hurricane Floyd: 7-17 September, 1999. - National Hurricane Center, Miami, FL.

Preston, F. W. 1960. Time and space and the variation of species. - Ecology 41: 785-790.

Preston, F. W. 1962a. The canonical distribution of commonness and rarity: part I. - Ecology 43: 185-215.

Preston, F. W. 1962b. The canonical distribution of commonness and rarity: part II. - Ecology 43: 410-432.

Schoener, T. W. 1976. The species-area relation within archipelagos: models and evidence from island land birds. - Proceedings of the 16th International Ornithological Conference, Australian Academy of Science, Canberra, pp. 629-642.

Schoener, T. W. 1983. Rate of species turnover decreases from lower to higher organisms: a review of the data. - Oikos 41: 372-377.

Schoener, T. W. 1987. Leaf pubescence in buttonwood: community variation in a putative defense against defoliation. - Proc. Natl Acad. Sci. USA 84: 7992-7995.

Spiller, D. A. and Agrawal, A. A. 2003. Intense disturbance enhances plant susceptibility to herbivory: natural and experimental evidence. - Ecology 84: 890-897.

Spiller, D. A. et al. 1998. Impact of a catastrophic hurricane on island populations. - Science 281: 695-697.

Spiller, D. A. and Schoener, T. W. 2007. Alteration of island food-web dynamics following major disturbance by hurricanes. - Ecology 88: 37-41.

SPSS 2007. 16.0.1 for Mac OSX. - SPSS, Chicago, IL.

Triantis, K. A. et al. 2006. Re-approaching the small island effect. - J. Biogeogr. 33: 914-923.

Vidal, E. et al. 2000. Seabirds drive plant species turnover on small Mediterranean islands at the expense of native taxa. - Oecologia 122: 427-434.

Whitehead, D. R. and Jones, D. E. 1969. Small islands and the equilibrium theory of insular biogeography. - Evolution 23: 171-179.

Wiens, H. J. 1962. Atoll environment and ecology. - Yale Univ. Press.

Whittaker, R. J. and Fernández-Palacios, J. M. 2007. Island biogeography: ecology, evolution, and conservation. - Oxford Univ. Press.

Williams, C. B. 1964. Patterns in the balance of nature. - Academic Press. 